Revista Educación 25(1): 35-52, 2001

\title{
PERCEPCIÓN DE LOS PROCESOS DE ENSEÑANZA Y APRENDIZAJE EN LA ESCUELA DE NUTRICIÓN DE LA UNIVERSIDAD DE COSTA RICA
}

\author{
Francisco Sánchez Montero
}

\begin{abstract}
Resumen: Para determinar la opinión de docentes y estudiantes de la Escuela de Nutrición, sobre los procesos de enseñanza y aprendizaje, se realizó una encuesta y analizó con base en la teoría sobre metáforas. Los resultados muestran la concepción docente acerca del conocimiento, de su rol como enseñante y las obligaciones y características que le atribuye al alumno. Entre las opiniones de los estudiantes, destacan su manera de entrar al proceso de aprender y mantenerse en él y su sentir hacia el rol del docente y el suyo propio. En este contexto, valora los contenidos teóricos y metodológicos de sus cursos, sus obligaciones de estudiante y expectativas profesionales, basadas en sus prejuicios acerca de la carrera que cursa. Se concluye que el sistema de creencias que define la praxis docente es unidireccional, adherido a los materiales de instrucción y a la ideología institucional que propicia la fantasía de que el trabajo docente subsana las ansiedades e ilusiones de su quehacer. Por su parte, en el sistema de creencias estudiantil media su preocupación de llevar la teoría a la práctica e identificarse con los valores de la sociedad, esperando que su estadia en la universidad solvente sus necesidades académicas, vocacionales y de desarrollo personal.
\end{abstract}

\section{Introducción}

Una reflexión sobre los procesos de enseñanza y de aprendizaje permite esclarecer en cierta medida, el sistema de creencias que versa sobre la enseñanza y el aprendizaje en grupos humanos expuestos a la práctica docente. A la vez, se derivan de este análisis referencias sobre el contexto socio-cultural de docentes y estudiantes. De acuerdo con varios autores (Borrowman, 1978; Ball, 1989; Cross y Thomas, 1991; Gurdián, 1991; Morgan y Jere, 1991; Nalús, 1992), este contexto es el lugar donde se gestan los antecedentes sociales, emocionales y culturales particulares de cada uno de los actores, y que aparecen amalgamados dentro de las condiciones ambientales en un espacio educativo.

Cuando estas situaciones ocurren en el aula universitaria, donde hoy se quiere dar importancia al proceso mismo de aprender y a la exigencia formativa, en lo referente al fomento de actitudes y aptitudes que contribuyan al logro de la calidad, resulta imprescindible, identificar los paradigmas bajo los cuales se ejerce la docencia universitaria, tal como lo comentan en sus obras Morgan y Jere (1991), Metz y McNeely (1991) y Fermoso (1995).

Una manera de abordar las mencionadas conceptualizaciones, siguiendo el pensamiento de Avery (1991), es realizando investigaciones de aula, en las cuales se pueda analizar la opinión externada por docentes y estudiantes universitarios. En este caso, la identificación de las 
"metáforas" surgidas del discurso docente-discente permite determinar esquemas de referencia para potenciar el desarrollo de la práctica docente en el aula universitaria.

\section{La práctica docente en la enseñanza superior}

\section{El sistema de creencias en la vida universitaria}

En uno de sus escritos, Abarca (s.f.), reflexiona que la pedagogía universitaria no es sólo un asunto de métodos, técnicas, programaciones y currícula, sino que tiene que ver, también, con el sistema de creencias que se forjan los docentes y las docentes para enfrentar los procesos de construcción del conocimiento y su rol en ellos. Explica que esto tiene que ver con la ideología a la que se adhieren, la que, entre otros aspectos, afecta sus relaciones vinculares con los estudiantes y las estudiantes, la organización, la metodología y los contenidos de los cursos.

Para Rowntree (1986), el sistema de creencias define la praxis docente, la cual está impregnada por la forma en que sus participantes (profesores, profesoras y estudiantes) interpretan los procesos de enseñanza y de aprendizaje a la luz de sus prejuicios y aspiraciones personales. De esta manera, extendiendo el pensamiento de autores clásicos dentro del estudio de los procesos grupales como Brichetto y Franzi de Brichetto (1974), todo curso, como elemento de estos procesos, es una construcción social que requiere su comprensión mediante el conocimiento de las expectativas de sus actores y de sus patrones de comunicación, con el fin de evaluar los logros vinculados con cambios en la vida diaria en el aula, esto es, en sus formas de funcionamiento social e individual, formas de conducta y relación con los demás.

Por otra parte, la práctica docente, tal y como la han conceptualizado entre otros, Abarca (s.f.), Adamson (s.f.), Contreras (s.f.) y Guebel y Rey (1992), ocurre en un contexto institucional donde se ponen en juego diversos esquemas conceptuales de referencia, relacionados con el pensamiento y el conocimiento, la emoción que impregna sus actitudes y la acción. Ese contexto incluye tanto los significados elaborados por los docentes y las docentes y estudiantes, como por las redes vinculares en cuanto al ejercicio del poder, las resistencias y los valores.

Para conocer los significados y las relaciones vinculares de los procesos de enseñanza y de aprendizaje, se parte de la premisa de que el ser humano construye su sistema de conceptos, y actúa en el mundo, percibiendo las relaciones con la gente y con lo que la rodea de manera metafórica, es decir, mediante analogías: asociando cada palabra de su lenguaje a una forma particular de pensar y entender las cosas y estructurando su experiencia en términos de otra, como ya ha sido planteado por Contreras (s.f), Singer (s.f) y Guebel y Rey (1992).

Los conceptos son, también, representaciones que se forman a partir de la experiencia y que afectan las relaciones con los grupos. Sirven como un cristal a través del que se interpreta y actúa, en otras palabras, son un vínculo formado mediante la representación y no por lo que ésta sea en la realidad. La complejidad del mundo de la vida, según es interpretada por Sternbach (c-s.f.) hace que surjan esquemas de referencia o de conceptos que evocan diversas vivencias y provocan dobles discursos o significados. Estos significados están cargados de afecto, el cual es importante en la representación, tanto que Kaës, psicoanalista francés contemporáneo, considera que el sistema de representaciones que constituye los grupos es un verdadero aparato psíquico grupal, cuya importancia radica en la posibilidad de organizar las inter-relaciones que ahí se dan y de facilitar u obstaculizar el proceso de cualquier grupo. En el caso presente, las representaciones de los procesos de enseñanza y de aprendizaje condicionarían el accionar educativo en el grupo humano de docentes y estudiantes, de aquí la importancia de reflexionar sobres estos significados. 


\section{Enseñar y aprender en la docencia universitaria}

Desde principios del siglo pasado, con el advenimiento de las novedosas corrientes psicológicas como las de Gessel, Freud, Thorndike, Skinner, Koffka, Werner y Piaget, para citar algunas, se postuló la estrecha relación de los métodos y técnicas de enseñanza con los diferentes aspectos del desarrollo del aprendizaje. Por eso es difícil referirse a un concepto sin involucrar al otro. Sin embargo, un común denominador de ambos, identificado por Arrién et al. (1996), García, Valle y Ferrer (1996) y Merz (1996), es la filtración de subjetividades inherentes al mundo interior del individuo, tanto del que enseña como del que aprende. Tales subjetividades se ven inhibidas o potenciadas en relación directa con el espacio físico y emocional intra-aula, y el contexto propio del colectivo pedagógico y de la comunidad donde se inserta la experiencia educativa.

Otro punto en común, de acuerdo con el planteamiento dado por Barrantes (1995), Lépiz (1995), Chaverri (1995) y García, Valle y Ferrer (1996), es que ambos conceptos implican procesos complejos, creativos, innovadores, que operan según las necesidades de los sujetos que los promueven y de quienes los reciben. Provocan transformaciones recíprocas entre enseñante y aprendiz, así esta convergencia se ve afectada por los valores, ideales y convicciones que parten de ambas direcciones.

Numerosas referencias sobre las cualidades del enseñar y del aprender en la docencia universitaria, presentadas en los trabajos de López (1989), Barrantes (1995), Arrién et al. (1996), Delors (1996) y Rodríguez (1997), enfatizan que en esta etapa se magnifican porque la gestión docente-educativa, según se concibe actualmente, tiene como perspectiva la búsqueda de la excelencia en todos los aspectos de su acontecer académico. No cabe duda, por lo tanto, que cualquier conceptualización sobre los elementos mencionados estaría incompleta si no se percibieran estos significados. Si así fuera, se daría testimonio de que la comprensión de ambos procesos ha evolucionado hasta implicar un grado mayor de conocimiento. Al decir de los filósofos de la Antigüedad, tal avance los colocaría en la categoría de un arte, ese que justamente debería asumir la docencia universitaria.

A fin de poder analizar total o parcialmente estas consideraciones, y asumiendo que en el ámbito de la docencia en salud existe una comunidad de docentes y discentes en la Escuela de Nutrición de la Facultad de Medicina, con una trayectoria relativamente corta dentro de la cultura institucional y donde, por lo tanto, no se ha hecho un análisis similar al propuesto en la teoría, se estimó conveniente abocarse a la siguiente metodología.

\section{Metodología}

Con base en los documentos de Abarca (s.f. y 1993) y Rowntree (1986), se elaboraron dos preguntas abiertas para docentes y estudiantes, respectivamente, de la Escuela de Nutrición (Anexos 1 a y b). La muestra de estudiantes $(n=25)$ fue intencional, debiendo cumplir con el requisito de estar en el último año de bachillerato de su Plan de Estudios a fin de suponer que tendrían un criterio más amplio sobre los procesos de enseñanza y aprendizaje desarrollados en la unidad académica. La muestra de docentes $(n=6)$, debió cumplir con el requisito de tener nombramiento en propiedad y ser Nutricionista. Ambas muestras, por ofrecer información de los casos más fácilmente accesibles, fueron calificadas como "muy cercanas" tal como las denomina Charest (1994). El cuerpo docente se contactó en los cubículos de la Unidad Académica ubicada fuera del campus de la Sede Central de la Universidad; y el estudiantil, en las clases de dos cursos de último año de Bachillerato en Nutrición, recibidos en diferentes aulas del Campus, durante 1996. Posteriormente, conforme lo indica el documento de Abarca, se hicieron planillas con los siguientes rubros para analizar el significado de enseñar y de aprender para los docentes: 


\section{ENSEÑANZA}

¿Quién tiene el conocimiento?

¿Dónde está el conocimiento?

¿Qué papel juega el/la docente?

¿Qué papel juega el/la alumno(a)?

\section{APRENDIZAJE}

¿Quién aprende?

¿Cómo aprende?

¿Qué hace el/la docente?

¿Qué hace el/la alumno(a)?
Para el análisis del significado de aprender por parte de los estudiantes y sobre lo que les significaba el curso que estaban recibiendo, se siguió el siguiente esquema:
¿Cómo perciben las clases desde lo conceptual?
¿Cuáles son sus prejuicios?
¿Cómo las perciben desde lo metodológico?
¿Qué esperan del curso?
¿Cuál es el rol del/la estudiante en el curso?
¿Qué actitud muestra el/la alumno(a)?
¿Cuáles son sus expectativas personales?
¿Cómo perciben la toma de decisiones en el curso?

Una vez agrupadas por separado las encuestas de estudiantes y docentes, cada una se leyó varias veces y se extrajo textualmente la frase o relaciones de palabras que fungieran como metáfora de los rubros mencionados. Seguidamente, en una planilla resumen se consignaron similitudes, diferencias, tendencias y patrones de las metáforas surgidas. Por último, se elaboró una síntesis interpretativa de las metáforas por cada rubro analizado. Esta etapa implicó la reflexión sobre la teoría de procesos grupales expuesta en el apartado anterior y la resumida por Garita, deBeausset y Podkaminsky (1994) y también recurrir a la experiencia de investigador, que le permitió observar y registrar, durante cuatro semestres la forma de trabajar y de pensar de estudiantes y docentes y replantearse a sí mismo sus conceptos sobre el particular.

La sistematización de fichas de autoevaluación, diseñadas por el autor de este trabajo como práctica de los cursos recibidos en el Departamento de Docencia Universitaria de la Facultad de Educación, durante 1994-96, permitió que sucesivos grupos de estudiantes, diferentes a los que participaron de esta experiencia, pero inmersos en las mismas condiciones de ausencia de infraestructura física propia -teniendo que ambular por diferentes recintos de la universidad- y sociohistóricas (cambio en los planes de estudio motivados por la apertura del Bachillerato y cierre de la Licenciatura), dispusieran de verdaderos "portafolios" donde podían testificar sobre su propio proceso de aprendizaje y revisar su posición ante la enseñanza impartida, y socializarla posteriormente en las sesiones de evaluación formativa de los cursos. La documentación de estos procesos fue material de ayuda para el análisis.

Una vez completada esta etapa, el trabajo se sometió a la consideración de especialistas en docencia universitaria y en desarrollo de conductas en contextos grupales. Sus sugerencias fueron incorporadas al análisis y sirvieron para estructurar una presentación sintética de estos resultados a los estudiantes que contestaron las preguntas y posteriormente, al personal administrativo y cuerpo docente de 
la Escuela de Nutrición. El objetivo fue recibir opiniones para validar de alguna manera el trabajo realizado.

Conviene aclarar que el número de docentes entrevistados correspondió al 50\% del total en propiedad y el de estudiantes, al 65\% del total matriculado en Bachillerato. El 100\% de docentes y el 98\% de estudiantes fue de sexo femenino. El proceso de investigación ocurrió entre los años 1995 y 1997.

\section{Resultados de la percepción docente}

\section{Acerca del concepto de enseñanza}

Metáfora sobre el poseedor del conocimiento

\begin{tabular}{|l|l|l|l|}
\hline \multicolumn{1}{|c|}{ SIMILITUDES } & DIFERENCIAS & TENDENCIA & PATRÓN \\
\hline $\begin{array}{l}\text {-a veces, el sujeto es } \\
\text { tácito }\end{array}$ & $\begin{array}{l}\text {-el conocimiento está en } \\
\text { el proceso que fascina } \\
\text { como un juego, siendo el } \\
\text { método y la técnica que } \\
\text {-tiene el papel clave } \\
\text { intereses en el alumnado }\end{array}$ & -descartar lo afectivo & $\begin{array}{l}\text {-limitado artar el entorno } \\
\text { momento de } \\
\text { la clase }\end{array}$ \\
$\begin{array}{l}\text {-es un motor que } \\
\text { transmite una parte de } \\
\text { algo que posee }\end{array}$ & & \\
\hline
\end{tabular}

Síntesis: extendiendo la teoría de grupos planteada por Bernard (s.f.), Sternbach (s.f.,b) y Brichetto y Franzi de Brichetto (1974), al campo de la educación, se puede decir que existen dos polos en la percepción sobre quién posee el conocimiento: uno, relacionado con la representación estereotipada del docente, visto en su papel unidireccional de transmisor sin reciprocidad manifiesta; mostrando además, de manera latente, la imagen del educando sometido a una autoridad, poseedora de la clave, del liderazgo. Esta situación revela también el sistema de representaciones de la cultura circundante que incide directamente en todo ser humano adulto.

El otro polo cosifica el conocimiento y lo circunscribe a la estructura del aula, donde a modo de reingeniería grupal, los métodos y las técnicas refuerzan una conducta positiva. Sin embargo, esta representación, a pesar de cumplir con los principios de la Didáctica, no considera la unicidad del proceso de enseñanza-aprendizaje, descartando lo afectivo y el entorno. Existe una identidad latente que habría que definir con más profundidad.

Metáfora sobre el lugar del conocimiento

\begin{tabular}{|c|c|c|c|}
\hline SIMILITUDES & DIFERENCIAS & TENDENCIA & PATRÓN \\
\hline $\begin{array}{l}\text {-en los materiales-libros, biblio- } \\
\text { grafía- } \\
\text {-en el cúmulo del saber } \\
\text {-en las condiciones técnicas, di- } \\
\text { dácticas, que permiten el proceso } \\
\text { de aprendizaje; en el contexto } \\
\text { donde se puede adquirir ese co- } \\
\text { nocimiento }\end{array}$ & $\begin{array}{l}\text {-el conocimiento se li- } \\
\text { mita a los dos polos } \\
\text { del proceso (educan- } \\
\text { do-facilitador), quienes } \\
\text { establecen una común } \\
\text { unión, una lógica de } \\
\text { comprensión de con- } \\
\text { ceptos }\end{array}$ & $\begin{array}{l}\text {-consiste en desligar la } \\
\text { afectividad de los conte- } \\
\text { nidos }\end{array}$ & $\begin{array}{l}\text {-existe la } \\
\text { creencia de } \\
\text { que el lugar } \\
\text { del conoci- } \\
\text { miento se } \\
\text { limita al es- } \\
\text { pacio físico } \\
\text { del aula }\end{array}$ \\
\hline
\end{tabular}


Síntesis: según algunos autores como Sternbach (s.f., a y c), Brichetto y Franzi de Brichetto (1974), D'Alvia (1986) y Guebel y Rey (1992), aceptar pasivamente las cosas que están en los materiales puede ser una proyección narcisista sobre los objetos que facilitaría el autoritarismo y representa también, autoalienación y adherencia a pensamientos ya enunciados por otros. Asumir esta posición, implica correr el riesgo de que a fin de evitar angustias, conflictos y diferendos para estar tranquilo, no se promueva ningún aprendizaje creativo ni democrático y, a la vez, se estimule el conocimiento frío, memorístico y sin posición crítica después del saber.

Por otra parte, las metáforas excluyen la vida cotidiana e indican el predominio de un esquema referencial de conceptos muy académico e intelectual (educando y facilitador esgrimen su lógica). En este caso, se perjudica el sentido de pertenencia e identidad del grupo, que no sería tal, sino más bien un "equipo de trabajo". Sin embargo, se podría favorecer el desarrollo personal al existir disociación entre los afectos y el reconocimiento de los otros.

Metáfora sobre el papel docente

\begin{tabular}{|l|l|l|}
\hline \multicolumn{1}{|c|}{ SIMILITUDES } & DIFERENCIAS & TENDENCIAS \\
\hline $\begin{array}{l}\text {-el docente es un padre benefac- } \\
\text { tor, ve las necesidades, codifica, } \\
\text { ordena. Es un estratega, un líder } \\
\text { que moviliza y enfatiza pasos a se- } \\
\text { guir y por lo tanto es un ejemplo } \\
\text { ya que tiene todas las claves, re- } \\
\text { suelve problemas y alivia las an- } \\
\text { siedades que produce el aprender }\end{array}$ & $\begin{array}{l}\text {-es un "medio" para que los } \\
\text { conocimiento }\end{array}$ & $\begin{array}{l}\text {-creen que su papel es } \\
\text { el de persuadir, entu- } \\
\text { siasmar al discente para } \\
\text { que aprenda }\end{array}$ \\
\hline
\end{tabular}

Sintesis: las metáforas representadas por este papel obedecen, de acuerdo con algunos esquemas teóricos discutidos por Sternbach (s.f.,c) y Bricheto y Franzi de Brichetto (1974), al deseo de evitar el conflicto, el dolor y el miedo a la inseguridad presente siempre en el individuo. Al idealizar el rol, el docente garantiza su saber y su poder pero no fomenta el aprendizaje de vínculos más creativos y democráticos. De igual modo, al obviar las dificultades y negaciones que suceden en la realidad, desvaloriza uno de los polos (el discente) en los procesos de enseñanza y de aprendizaje. Finalmente, la tendencia reafirma estas representaciones al desconocer la alteridad y recurrir a la seducción y a la coacción para lograr sus fines. 
Metáfora sobre el papel del alumno

\begin{tabular}{|c|c|c|}
\hline SIMILITUDES & DIFERENCIAS & TENDENCIAS \\
\hline $\begin{array}{l}\text {-es el "receptor", un ser pasivo engra- } \\
\text { nado en un proceso } \\
\text {-operario que trabaja con diversos ma- } \\
\text { teriales, por tanto debe ser un artista } \\
\text { también } \\
\text {-es un ayudante valioso en la escena } \\
\text {-"socio", "contraparte" de una acción } \\
\text {-es el objeto del experimento }\end{array}$ & $\begin{array}{l}\text {-considera al alumno } \\
\text { como una unión entre } \\
\text { la academia y el medio } \\
\text { socio-cultural } \\
\text {-el alumno aprende a } \\
\text { ser como "el otro", se } \\
\text { nutre de su lógica, pero } \\
\text { es responsable de am- } \\
\text { pliar y actualizar el } \\
\text { conocimiento }\end{array}$ & $\begin{array}{l}\text {-por un lado creer que es } \\
\text { una figura pasiva, inválida, } \\
\text { expectadora; y por otro, } \\
\text { como ser activo, sabotea- } \\
\text { dor, inquieto, cuestionador } \\
\text { permanente, autosuficiente }\end{array}$ \\
\hline
\end{tabular}

Sintesis: la representación de estas metáforas indica que es un rol complementario al del docente. Sternbach (s.f.,c) afirma que esta representación social corresponde a un modelo organizado de conducta apto para facilitar la tarea. No obstante, en otras circunstancias, el rol se vuelve en parte suplementario, sustitutivo, sobre todo cuando se trata de adquirir vivencias fuera de la academia. Con esto, y la tendencia a hacerle otras depositaciones, se originan metáforas que representan un rol cambiante y permeable a los afectos y a la interacción grupal.

\section{Acerca del concepto de aprendizaje}

Metáfora sobre el concepto del sujeto que aprende

\begin{tabular}{|c|c|c|c|}
\hline SIMILITUDES & DIFERENCIAS & TENDENCIAS & PATRÓN \\
\hline $\begin{array}{l}\text {-aprende el que "se vincula } \\
\text { desde el punto de vista afec- } \\
\text { tivo con el aprendizaje" } \\
\text {-el "volitivo", el "hábil", } \\
\text { "diestro", el que internaliza y } \\
\text { reflexiona } \\
\text {-el que sensiblemente se } \\
\text { "fascina y contenta", esti- } \\
\text { mulando a tal grado su } \\
\text { creatividad que puede de- } \\
\text { velar los "códigos ocultos } \\
\text { del docente" }\end{array}$ & $\begin{array}{l}\text {-el que aprende es solamen- } \\
\text { te una persona práctica, ra- } \\
\text { cional, que se organiza para } \\
\text { tomar decisiones } \\
\text {-es el que construye } \\
\text {-el que pone límites, traza } \\
\text { líneas, perspectivas y una } \\
\text { visión de más allá }\end{array}$ & $\begin{array}{l}\text {-de vincular el } \\
\text { aprendizaje a la } \\
\text { afectividad, consi- } \\
\text { derando a quien } \\
\text { aprende como un } \\
\text { individuo carente, } \\
\text { con una necesidad } \\
\text { básica primaria que } \\
\text { puede subsanar el } \\
\text { docente, llegando } \\
\text { al corazón del } \\
\text { alumno }\end{array}$ & $\begin{array}{l}\text {-existe la } \\
\text { creencia de } \\
\text { que el } \\
\text { aprendizaje } \\
\text { es una mi- } \\
\text { sión de fe, } \\
\text { del conver- } \\
\text { tido al que } \\
\text { le ha llega- } \\
\text { do el mo- } \\
\text { mento de } \\
\text { reflexionar }\end{array}$ \\
\hline
\end{tabular}


Síntesis: la representación metafórica del que aprende coincide con el encuadre de la institución, su ideología y con la tendencia a considerar incompleto y carente de algo al ser humano sometido a una experiencia docente. Por otra parte, esta representación es producto de ligazones afectivas, que según Bernard (s.f.), hace que el "grupo interno" del docente constituido por sus expe- riencias, genes y mundo interno, se proyecte sobre la estructura de roles dados, para abordar al discente. Asimismo, los vínculos surgidos tienen una direccionalidad, buscan satisfacer las necesidades de enseñanza y de aprendizaje de ambos grupos, originando reciprocidad. La satisfacción vincular dada provoca una sensación de pertenencia y de logro de identidad.

Metáfora sobre cómo se aprende

\begin{tabular}{|c|c|c|c|}
\hline SIMILITUDES & DIFERENCIAS & TENDENCIAS & PATRÓN \\
\hline $\begin{array}{l}\text {-se aprende de manera muy } \\
\text { individual }\end{array}$ & $\begin{array}{l}\text {-se aprende mediante la } \\
\text { reflexión que lleva al } \\
\text { "éxtasis" } \\
\text {-conectando cosas, } \\
\text { construyendo } \\
\text {-adueñándose del co- } \\
\text { nocimiento } \\
\text {-aprovechando oportu- } \\
\text { nidades } \\
\text {-unificándose con el } \\
\text { docente } \\
\text {-poniendo en práctica } \\
\text { lo aprendido }\end{array}$ & $\begin{array}{l}\text {-se aprende "aplicando } \\
\text { los conocimientos inte- } \\
\text { riorizados" }\end{array}$ & $\begin{array}{l}\text {-se asocia el } \\
\text { cómo se } \\
\text { aprende a los } \\
\text { aspectos de } \\
\text { docencia, in- } \\
\text { vestigación y } \\
\text { acción social }\end{array}$ \\
\hline
\end{tabular}

Síntesis: estas metáforas se pueden ligar al concepto de institución como espacio psíquico, sustentado por Brichetto y Franzi de Brichetto (1974) y Guebel y Rey (1992). En éste, se vehiculizan los aspectos más maduros del individuo (sublimar, socializar, transformarse), promoviendo un alumno que, en solitario, resuelve el proceso de apropiación instrumental de la realidad, en aras de convertirse en agente de trabajo y producción. 
Metáfora sobre el quebacer del alumno

\begin{tabular}{|c|c|c|}
\hline SIMILITUDES & DIFERENCIAS & PATRÓN \\
\hline $\begin{array}{l}\text {-es un comprador que ad- } \\
\text { quiere una mercancía, se } \\
\text { siente motivado y vinculado } \\
\text { afectivamente para adquirirla } \\
\text {-elige lo nuevo de la última } \\
\text { moda presentada por el do- } \\
\text { cente. Se somete a esa moda } \\
\text { una vez que la decodifica, o } \\
\text { sea, la asocia a su saber y ex- } \\
\text { periencia }\end{array}$ & $\begin{array}{l}\text {-el trabajo del alumno es una lucha } \\
\text {-se expone a perder o a ganar } \\
\text {-puede ser sometido a un cambio } \\
\text { puede vencer y adueñarse del co- } \\
\text { nocimiento, lo que amerita su par- } \\
\text { ticipación activa y captar la oportu- } \\
\text { nidad de acción }\end{array}$ & $\begin{array}{l}\text {-consiste en creer que el } \\
\text { alumno discierne sobre su } \\
\text { felicidad, a una vida mejor } \\
\text { una vez que haya "asimila- } \\
\text { do", "transformado", "actua- } \\
\text { lizado" conocimientos, los } \\
\text { lleva a su cotidianidad y su } \\
\text { luz que era pequeña, se } \\
\text { agranda }\end{array}$ \\
\hline
\end{tabular}

Síntesis: el quehacer del alumno evoca en el docente una serie de metáforas propias de su esquema conceptual de referencia y de su afectividad, lo que conforma un sistema de representaciones en la micro cultura del aula. Este sistema aparece bidireccional, mezcla de actitudes cognitivas (intelectuales) y afectivas y de acción concreta sobre el medio. Priva aquí el sentimiento de que los aprendizajes deben ser instrumentos de comprensión, acción y modificación de esquemas anteriores.

Metáfora sobre el quebacer del docente

\begin{tabular}{|c|c|c|c|}
\hline SIMILITUDES & DIFERENCIAS & TENDENCIAS & PATRÓN \\
\hline $\begin{array}{l}\text {-el docente primero crea } \\
\text { una atmósfera mística pa- } \\
\text { ra interiorizar actitudes y } \\
\text { conocimientos. Promete } \\
\text { logro, dicha } \\
\text {-siente un "contento" por } \\
\text { "entrar" al individuo, no } \\
\text { al grupo } \\
\text {-separa, moviliza senti- } \\
\text { mientos, saca creaciones } \\
\text { del interior } \\
\text {-da herramientas para lle- } \\
\text { varlas a la realidad }\end{array}$ & $\begin{array}{l}\text {-el docente sólo muestra } \\
\text { conocimientos, habilida- } \\
\text { des, destrezas } \\
\text {-omite lo afectivo } \\
\text {-hace gala de su saber, } \\
\text { proyectándolo continua- } \\
\text { mente }\end{array}$ & $\begin{array}{l}\text {-existe la tendencia a } \\
\text { ver al docente como } \\
\text { depositario del saber } \\
\text { y por otro lado como } \\
\text { facilitador, moldeador } \\
\text { de sentimientos y } \\
\text { pensamientos }\end{array}$ & $\begin{array}{l}\text { - promociona } \\
\text { utilizando el } \\
\text { mejor mensaje, } \\
\text { para que ad- } \\
\text { quieran un traje } \\
\text { nuevo }\end{array}$ \\
\hline
\end{tabular}


Sintesis: la representación que se da en estas metáforas corresponde a una identificación primaria de grupo ideal, que promete reconocimiento, además, el establecimiento de vínculos, que Adamson (s.f.), D’Alvia (1986) y
Bernard (1990) entrecruzan con el esquema referencial de cada uno de los actores, que en este caso operan en la escena del aula universitaria. Entonces, este quehacer docente puede ser la fantasía de contener ansiedades e ilusiones.

\section{Resultados de la percepción de los estudiantes}

\section{Acerca del concepto de aprendizaje}

Metáfora sobre el concepto del sujeto que aprende

\begin{tabular}{|c|c|c|}
\hline SIMILITUDES & DIFERENCIAS & TENDENCIA \\
\hline $\begin{array}{l}\text {-aprende la persona que "adquie- } \\
\text { re", "toma" conocimientos especí- } \\
\text { ficos, vinculados a un proceso } \\
\text {-puede pasar por varias etapas } \\
\text { que van desde la carencia de sa- } \\
\text { beres, por lo que debe "buscar sa- } \\
\text { biduría" } \\
\text {-se puede quedar en ese estado, } \\
\text { fascinándose con el conocimien- } \\
\text { to, "descubriendo" cosas, abrien- } \\
\text { do sus "puertas" al mundo del } \\
\text { conocimiento, "escuchando", } \\
\text { "apropiándose del conocimiento } \\
\text { básico", "enriqueciendo" su } \\
\text { mente, "interiorizando conoci- } \\
\text { mientos" } \\
\text {-puede seguir adelante, llevando } \\
\text { un "arma", "herramienta", "mol- } \\
\text { dear su vida" y "modificar su ac- } \\
\text { titud" }\end{array}$ & $\begin{array}{l}\text {-algunos consideran que se } \\
\text { aprende desde una perspec- } \\
\text { tiva interna y nada más (es- } \\
\text { cuchando, enriqueciéndose) } \\
\text {-otros, sólo desde la cotidia- } \\
\text { nidad de la vida, "transpor- } \\
\text { tando" lo teórico al diario } \\
\text { vivir }\end{array}$ & $\begin{array}{l}\text {-se aprende sólo vincu- } \\
\text { lando lo teórico con lo } \\
\text { práctico } \\
\text {-también "investigando" } \\
\text { "problematizando" }\end{array}$ \\
\hline
\end{tabular}

Sintesis: la metáfora representada por los estudiantes acerca del sujeto que aprende obedece a un esquema referencial de conceptos acorde con los planteamientos teóricos sobre el aprendizaje. El conocimiento no se capta de manera inmediata, sino que requiere un proceso paulatino, en vista de que el objeto del deseo se resiste al cambio. Se nota una gran preocupación por llevar lo teórico al diario vivir, para crear un objeto del conocimiento - que no existe- mediante la creatividad y el trabajo. 
Metáfora sobre la manera de aprender

\begin{tabular}{|c|c|c|}
\hline SIMILITUDES & DIFERENCIAS & TENDENCIAS \\
\hline $\begin{array}{l}\text {-se aprende poniendo en } \\
\text { práctica los conocimientos } \\
\text { y la información recibida } \\
\text {-uniendo conocimientos y } \\
\text { vivencias } \\
\text {-para esto se requiere "fuer- } \\
\text { za", "poder", "voluntad" pa- } \\
\text { ra salir de la ignorancia y } \\
\text { del miedo de "transitar" por } \\
\text { lo desconocido }\end{array}$ & $\begin{array}{l}\text {-unos creen que se aprende } \\
\text { siendo un espectador, "viendo } \\
\text { los resultados de una aplica- } \\
\text { ción teórica", "detallando as- } \\
\text { pectos" } \\
\text {-otros, piensan que se apren- } \\
\text { de sólo compartiendo conoci- } \\
\text { mientos, explicando a otro, } \\
\text { "saliendo de sí" }\end{array}$ & $\begin{array}{l}\text {-una tendencia centra el } \\
\text { aprender en el sujeto como } \\
\text { receptor } \\
\text {-otra, centra el aprender en el } \\
\text { sujeto como ejecutor extra- } \\
\text { muros del aula }\end{array}$ \\
\hline
\end{tabular}

Síntesis: la manera de aprender es representada metafóricamente desde el grupo interno y por fantasías ligadas a escenas que constituyen la identidad de un proceso ideal de aprendizaje. Bernard (s.f. y 1988) contempla también que el aprender de la realidad no reproduce, sino que produce, llenando vacíos en el conocimiento. No se excluye el dilema de la antinomia sobre el cómo se aprende: individualmente, siendo receptor, o fuera del contexto del aula, en la sociedad.

Metáfora del rol docente

\begin{tabular}{|c|c|}
\hline SIMILITUDES & DIFERENCIAS \\
\hline $\begin{array}{l}\text {-dios olímpico: "presenta", "da cosas", "vacía } \\
\text { conocimientos" } \\
\text {-democrático benévolo: comparte "su sabidu- } \\
\text { ría", "explica", "plantea un proceso" } \\
\text {-paternalista: "ofrece conocimientos", "solucio- } \\
\text { na problemas", "retroalimenta", "permite que } \\
\text { el alumno crezca y avance" } \\
\text {-juez: "emite palabras", "mensajes", "evalúa", } \\
\text { "examina". }\end{array}$ & $\begin{array}{l}\text {-su rol es el de la parte afectiva: "enseña para } \\
\text { la vida", "refuerza el aprendizaje", "ofrece con- } \\
\text { ceptos" } \\
\text {-para otros, su rol es sólo comparable al de una } \\
\text { computadora que "da mensajes", sin ideas pro- } \\
\text { pias, sentimientos, deseos }\end{array}$ \\
\hline
\end{tabular}

Síntesis: en este aspecto, el grupo estudiantil ve el papel docente desde una perspectiva alienadora. El/la estudiante la acepta, se identifica con ella, se siente unido(a) afectivamente y la idealiza porque le significa su realidad. Sin embargo, el rol está descontextualizado, no se ven sus aristas sociales ni se consideran sus vínculos, en suma, no se tiene la representación de dos personas ayudándose a aprender. Tal representación coincide con la forma de ejercer y simbolizar una tarea circunscrita a la cultura institucional, desde donde "se marca la cancha", tal como lo han planteado Sternbach (a y c), Brichetto y Franzi de Brichetto (1974) y Guebel y Rey (1992). 


\begin{tabular}{|c|c|}
\hline SIMILITUDES & DIFERENCIAS \\
\hline $\begin{array}{l}\text {-visionario que "busca adquirir la sabiduría", } \\
\text { aprender de los demás, descubrir los códigos pro- } \\
\text { pios de su profesión, poner en juego actitudes } \\
\text {-intelectual cuyo conocimiento debe ser alimen- } \\
\text { tado, "metabolizado" "para enriquecer", "nutrir" } \\
\text { su mente } \\
\text {-plagiario de un "profesional" porque pone en } \\
\text { práctica todo lo que se le indica, maneja lo posi- } \\
\text { tivo y lo negativo de lo aprendido } \\
\text {-receptor selectivo de lo que más le interesa } \\
\text {-implementa el proceso en todos sus quehaceres }\end{array}$ & $\begin{array}{l}\text {-unos ven su rol muy social "compartir", "asumir } \\
\text { responsabilidades", "transitar" } \\
\text {-otros, le atribuyen un poco de autoestima, } \\
\text { puesto que "espera aprender de los demás", } \\
\text { "vislumbrar otras realidades" }\end{array}$ \\
\hline
\end{tabular}

Síntesis: las metáforas indican una variada representación de sí mismos, como estudiantes. Muestran un sistema de creencias identificado con los valores vigentes en la sociedad y con la ideología sobre los procesos vinculares de poder, propios del ambiente institucional académico donde buscan apropiarse del conocimiento que carecen.

\section{Acerca del curso que está recibiendo}

Metáfora de la percepción conceptual de las clases

\begin{tabular}{|c|c|c|}
\hline SIMILITUDES & DIFERENCIAS & TENDENCIAS \\
\hline $\begin{array}{l}\text {-lo conceptual es percibido como de- } \\
\text { sacreditador de lo viejo } \\
\text {-buscan "obtener nuevos temas" } \\
\text {-inquisidora: "saca del alumno lo que } \\
\text { posee" } \\
\text {-caja negra: "presenta mucha materia" } \\
\text {-es débil: "es sólo un punto de partida } \\
\text { básico para un trabajo técnico" } \\
\text {-administrativa: "brinda eficiencia" }\end{array}$ & $\begin{array}{l}\text {-en un extremo se percibe } \\
\text { como "memorística", "no } \\
\text { necesaria" porque "lo que } \\
\text { se da se puede consultar en } \\
\text { otros ámbitos" } \\
\text {-en otro extremo es percibi- } \\
\text { da como un "aprender-ha- } \\
\text { ciendo" } \\
\text {-la materia es transmisión }\end{array}$ & $\begin{array}{l}\text { de poder, apoderación } \\
\text { de emblemas que lo } \\
\text { harán un profesional }\end{array}$ \\
\hline
\end{tabular}

Síntesis: lo conceptual de las clases conforma una representación social de los mitos, ritos e ideologías propios de la microcultura del aula. En este espacio se canalizan, también, diversos aspectos de la personalidad de los alumnos, que de acuerdo con la teoría expuesta por Adamson (s.f.), Singer (s.f), Bernard (1988) y Guebel y Rey (1992) van aparejados a su realidad social y a sus fantasías más estructuradas. 
Metáfora de la percepción metodológica de las clases

\begin{tabular}{|c|c|c|}
\hline SIMILITUDES & DIFERENCIAS & TENDENCIAS \\
\hline $\begin{array}{l}\text {-la metodología es percibida } \\
\text { como esquemática y evaluativa } \\
\text { "porque la teoría se evalúa en } \\
\text { la práctica" } \\
\text {-racionalizadora: "guía, da el } \\
\text { cómo, una visión profesional } \\
\text { diferente" } \\
\text {-manual de operaciones: "per- } \\
\text { mite aprender a transmitir } \\
\text { mensajes" } \\
\text {-esotérica: el docente aplica } \\
\text { métodos de "iniciación para } \\
\text { la tarea", una misión que le } \\
\text { pondrá en contacto con "otra } \\
\text { realidad" } \\
\text {-gerencial: "plantea problemas" }\end{array}$ & $\begin{array}{l}\text {-unos creen que en la parte } \\
\text { metodológica, el docente } \\
\text { permite al alumno trabajar, } \\
\text { crecer, desenvolverse } \\
\text {-otros la perciben como algo } \\
\text { que no permite al alumno } \\
\text { prepararse para un trabajo } \\
\text { futuro }\end{array}$ & $\begin{array}{l}\text {-verla como un espacio apto } \\
\text { para el desarrollo de habili- } \\
\text { dades y destrezas, "mete" al } \\
\text { estudiante, lo "involucra" en } \\
\text { un trabajo específico de su } \\
\text { futura profesión }\end{array}$ \\
\hline
\end{tabular}

Sintesis: las metáforas corresponden a un traslape de los vínculos del grupo interno particular de cada alumno(a), con los del grupo externo del desempeño de la profesión. Pa- ra Bernard (1990), es aquí donde se descargan los instintos originados en la fantasía del aprender, como un recurso para no caer en el miedo a enfrentar todo lo novedoso de su saber.

\section{Metáfora de las relaciones del}

estudiante con el curso

Aquí se aprecia a sí mismo como receptor de temas, actividades y prácticas.

El curso es su vinculante afectivo ya que le permite "ver" problemas.

Lo que la gente padece, afina el área profesional de su predilección.

Síntesis: el rol representado es coincidente con el rol docente. Por esta razón, los vínculos afectivos no salen de la cancha marcada en el curso (temas, actividades y prácticas), siendo liberados en otro contexto, donde existe una carencia capaz de movilizar los afectos de su esquema referencial, de su propia organización interna.

\section{Metáfora de los prejuicios del estudiante}

Cree que la academia le permitirá comprender la realidad de la sociedad y le capacitará para "transmitir mensajes" y tener "poder" sobre la gente, porque el aprendizaje sirve para controlar la vida, interpretarla ("tratar información") e indagar. 
EDUCACIÓN

Síntesis: las metáforas sobre estos prejuicios representan un ajuste individual de cada alumno(a) con la lógica y los valo- res que permean la sociedad actual, donde, con frecuencia, se avala el poder y el doble discurso.

\section{Metáfora de las expectativas del alumno}

Desenvolverse en actividades propias del campo profesional. Trabajar satisfactoriamente en comunidad, retribuirles en algo, contactando profesionalmente a los otros.

También, centrándose más en su propia personalidad, está el comprender la realidad, escudriñarla, fusionar conocimiento, ser diferente, sacar cosas de sí.

Síntesis: en relación con su futuro papel profesional, surge la apropiación de un esquema referencial orientado hacia dos interpretaciones: una claramente referida al ejercicio liberal, a ser fagocitado por los cánones de la cultura; otra, a no ejercer, porque mostrarse es atemorizante por el hecho de ser diferente.

Metáfora de las expectativas del curso

La mayoría espera un desarrollo personal para desenvolverse, ver a los otros, ser distinto, sacar mucho provecho del curso

Síntesis: la metáfora escenifica tres representaciones que responden a los intereses del grupo estudiantil: vocacional, académica y de desarrollo personal. Todas se basan en las representaciones sociales del grupo, que Sternbach (s.f,b), Singer (s.f.) y Rowntree (1986) han asociado con los mitos, ritos e ideologías del entorno, a manera de no ser desacreditados por la mirada social.

Metáfora de cómo perciben la toma

de decisiones en el curso

Cree que la toma de decisiones se hace llevando a la práctica el conocimiento, enfrentando la realidad, interactuando, viendo otros puntos de vista, señalando lo novedoso, manejando mucha información, investigando, planificando el trabajo, siguiendo una ley.

Síntesis: lo que impregna esta metáfora es la acción de alerta, el tiro al blanco, para cerrar todos los portillos a la frustración, al fracaso, al retroceso, que son otra manera de aprender, crecer y ser creativo. 


\section{Metáfora de la actitud que \\ muestra el alumno}

Predomina la actitud quejumbrosa e intolerante

("me afecta que pongan tantos informes", "afecta mi tiempo")

Síntesis: el símbolo que mediatiza esta percepción es el de los afectos negativos surgidos de una situación dramática, producida por la fragilidad y explotación de los actores.

\section{Conclusión}

El análisis de los anteriores resultados permite concluir que el cuerpo docente percibe sus relaciones, dentro de los procesos de enseñanza y de aprendizaje, de una manera estereotipada en cuanto a su rol, se ve como un simple transmisor del conocimiento y poseedor de la clave de su saber particular. El rol es idealizado de manera unidireccional, sin reciprocidad con el discente, centrado al espacio del aula, donde el uso de métodos y técnicas son una estrategia para estimular una conducta de aprendizaje escasa de vínculos afectivos positivos. Esto provoca una identidad grupal que necesita definirse. Asímismo, la auto-adherencia a pensamientos ya enunciados en los materiales de clase, afecta el aprendizaje creativo y crítico, a favor de uno memorístico y poco democrático. Surge entonces, como contraparte, el deseo de evitar angustias, diferendos y conflictos, negándose las dificultades y frustraciones que suceden en la realidad de la vida. Por eso, el rol del discente se ve tanto de manera complementaria (facilitador de la tarea) como suplementaria (competitivo con el docente), lo que permite que sea permeable a los afectos y favorecedor de la interacción grupal. Bajo este marco, se aprende de acuerdo con el encuadre e ideología institucional que avala el poder del docente por considerar que cubre la incompletud del alumno. También este encuadre condiciona el trabajo en el aula, haciéndolo propicio para el desarrollo de la fantasía de ser el contenedor de las ansiedades e ilusiones presentes en los procesos de enseñanza y de aprendizaje, pudiéndolas sublimar, socializar, transformar.

Por otra parte, se concluye que el grupo estudiantil percibe su relación con los procesos de enseñanza y de aprendizaje de manera cautelosa, entrando a ellos de manera paulatina, con gran preocupación por llevar lo teórico a la práctica y crear su propio objeto del conocimiento, que parece no existir. El aprender de la realidad práctica hace al grupo productor en vez de reproductor, pero descontextualiza la función del docente, obviando percibirla como un elemento que le ayudará a aprender. Esta actitud se ve favorecida por la tendencia a adherirse a los valores vigentes en la sociedad y en el contexto institucional, que estimulan el acaparamiento de diversos poderes. Es por este motivo que los conceptos externados en los cursos se manejan de acuerdo con los ritos, mitos e ideologías propias de la micro-cultura del aula, considerada un lugar para canalizar diversos aspectos de su personalidad y de sus fantasías, entre ellas, la de aprender procesos metodológicos que les ayuden a capturar el anhelado saber de su campo profesional. No obstante, sus expectativas futuras son dos: ser fagocitados por los cánones de la cultura o no ejercer para evitar el temor de ser catalogados como diferentes. A pesar de esto, esperan que la universidad solvente sus expectativas académicas y de desarrollo personal ya que el poder transmitir, controlar, subsanar, evitará el descrédito social. Para esto no se contempla el fracaso en la toma de decisiones, no se le aprecia como una forma de aprender, crecer y ser creativo. Es posible que estar en estado de alerta genere una actitud general pesimista, cargada de drama por percibirse como individuos frágiles y explotados. 


\section{Referencias bibliográficas}

Abarca, S. ¿Cómo reflexionamos sobre nuestra propia praxis? Universidad de Costa Rica. Facultad de Educación. Departamento de Docencia Universitaria. (s.f.).

Abarca, S. Metáforas: la construcción de una perspectiva. Heredia: Universidad $\mathrm{Na}-$ cional. 1993.

Adamson, G. Las organizaciones efimeras y las nuevas formas de agrupamiento social. Buenos Aires, Argentina: Ediciones Cinco. (s.f.).

Arrién, J.b; Bernal, J.B; Ooijens, J; Picón, C. y Thybergin, A. Calidad de la educación en el istmo centroamericano. UNESCO, San José: Talleres Gráficos Impresora Obando, S.A. 1996.

Avery, C. Aprender cómo se investiga. Investigar cómo se aprende. En: Olson, M. (Comp.). La investigación-acción en el aula. Argentina: Aique Grupo Editor 1991.

Ball, S. La micropolitica de la escuela. Hacia una teoría de la organización escolar. Argentina: Ediciones Paidós. 1989.

Barrantes, R. El profesor universitario ante el reto que representa el proceso de Enseñanza-Aprendizaje. Repertorio Científico, UNED, 3(1):35-39. 1995.

Bernard, M. Mundo Interno-Grupo Interno. Historia del concepto de Grupo Interno. Enfoque sociológico, psicosocial y psicoanalítico. Buenos Aires, Argentina: Instituto de Psicoanálisis de las Configuraciones Vinculares. (s.f.).

Bernard, M. La constitución del grupo interno. Buenos Aires, Argentina: Instituto de Psicoanálisis de las Configuraciones Vinculares. 1988.

Bernard, M. La fantasía en la organización del vínculo. Seminario de Configuraciones Vinculares. Buenos Aires, Argentina: Instituto de Psicoanálisis de las Configuraciones Vinculares. 1990.

Borrowman, M. Teacher education in America. Berkeley: University of California. 1978.

Brichetto, O.S. y Franzi de Brichetto, A. Tres Clases sobre ECRO. Argentina: Universidad Nacional de Córdoba, Facultad de Humanidades. 1974.

Contreras, I. El análisis de las metáforas que utilizamos diariamente: una alternativa metodológica para reflexionar acerca de nuestra práctica docente. Universidad de Costa Rica, Facultad de Educación, Departamento de Docencia Universitaria (s.f.).

Cross, P. y Thomas, A. Classroom Assessment Techniques. A Handbook for Faculty National Center for Research to Improve Post-Secondary Teaching and Learning. In: Resources in Education Abstracts. Part One. 1991.

Charest, P. Etnometodología e investigación en educación. Trad. K. Jiménez. Revue de Sciences de l'Education. Universitè de Quebec. Vol. XX. 1994.

Chaverri R., M.M. El adulto: algunas consideraciones para identificarnos con nuestros estudiantes. Innovaciones Educativas, UNED, III(6):29-36. 1995.

D’Alvia, R. Psicoanálisis y poder. En: Argentina, psicoanálisis, represión, política. Cap. Instituciones y violencia. Buenos Aires: Ediciones Kargieman. 1986. 
Delors, J. La educación encierra un tesoro. Comisión Internacional sobre la educación para el siglo XXI. Informe de la UNESCO. Madrid: Santillana, S.A. 1996.

Fermoso, J. Relaciones internacionales en la autosuficiencia de las universidades. Clase inaugural del Año Académico, 20-marzo-1995. UCR: Facultad de Agronomía. 1995.

García R., L.J.; Valle, L.A. y Ferrer I, M.A. Autoperfeccionamiento docente y creatividad. La Habana, Cuba: Editorial Pueblo y Educación. 1996.

Garita, C.; deBeausset, I y Podkaminsky, M. Encuadre teórico. San Pedro, Costa Rica: Con-Texto Grupal, Centro de Investigación y Formación en Procesos Grupales. 1994.

Guebel, A. y Rey, R.M. El espacio psíquico institucional: encierro o apertura. Revista de Psicología y Psicoterapia de Grupo, (2):147-162. 1992.

Gurdián, A. Modelo de evaluación curricular (MECAR II). Universidad de Costa Rica, Vicerrectoría de Docencia. Centro de Evaluación Académica. 1991.

Lépiz J., C.H. Martín Buber y la educación de adultos. Innovaciones Educativas, UNED, III(5):15-17. 1995.

López L., M. Cómo enseñar a determinar lo esencial. La Habana, Cuba: Editorial Pueblo y Educación. 1989.

Merz R., P. Algunas reflexiones epistemológicas sobre el aprendizaje participativo Memoria Congreso Internacional de Epistemología y Educación. San José, Costa Rica: EUNED. 1996.
Metz, N. y McNeely, S. How Professors "Learn" to Teach. Cognition, Teaching, Paradigms and Higher Education. In: Resources in Education Abstracts. Part One. 1991.

Morgan, O. y Jere, M. A. Crucial Agenda: Making Collegues and Universities Work Better for Minority Students. Western Interstate Commission for Higher Education. In: Resources in Education Abstracts. Part One. 1991.

Nalús P., M. Formación integral y conocimiento. Prevención integral en la Educación. Santa Fé de Bogotá, Colombia: Mimeografiado. 1992.

Rodríguez, R. El fenómeno del conocimiento humano. Innovaciones Educativas, UNED, IV(7):101-109. 1997.

Rowntree, D. Preparación de cursos para estudiantes. Barcelona: Editorial Herder. 1986.

Singer, D.S. La cultura, los ideales y el grupo. Buenos Aires, Argentina: Asociación Argentina de Psicología y Psicoterapia de Grupo. (s.f.).

Sternbach, S. Autoritarismo y pensamiento. Buenos Aires, Argentina: Asociación Argentina de Psicología y Psicoterapia de Grupo. (s.f., a).

Sternbach, S. Grupos y macrocontexto. Buenos Aires, Argentina: Asociación Argentina de Psicología y Psicoterapia de Grupo. (s.f., b).

Sternbach, S. Claves psíquicas del autoritarismo. Buenos Aires, Argentina: Asociación Argentina de Psicología y Psicoterapia de Grupo. (s.f., c). 
Anexos

\section{Anexo a: encuesta dirigida al cuerpo docente}

"A fin de realizar un análisis sobre el quehacer del docente y del estudiante de la Escuela de Nutrición, le solicito muy atentamente lo siguiente:

describir lo que significa para usted ENSEÑAR

describir lo que significa APRENDER. Gracias"
Anexo b: encuesta dirigida al grupo estudiantil

"A fin de presentar un análisis sobre el quehacer del docente y del estudiante de la Escuela de Nutrición, le solicito muy atentamente lo siguiente:

- $\quad$ hacer una introspección muy personal y describir lo que significa para usted EL CURSO QUE ESTÁ RECIBIENDO

describir lo que significa para usted qué es APRENDER. Gracias" 